\title{
THE FLEXURAL MOTIONS OF A FLOATING ICE SHEET INDUCED BY MOVING VEHICLES
}

\author{
By D. EYRE \\ (Saskatchewan Research Council, 30 Campus Drive, Saskatoon, Saskatchewan $\mathrm{S}_{7} \mathrm{~N}$ oX $\mathrm{I}$ \\ Canada)
}

\begin{abstract}
An extensive series of tests has been conducted on a floating ice sheet on a deep, fresh-water lake. A variety of vehicles were driven along an instrumented test track at a wide range of speeds, producing several characteristic patterns of ice and water response that have been recorded and analysed in detail. Tests were repeated at different stages of ice growth to accommodate changes in physical conditions. The use of a vibration transducer and a new type of deflectometer has permitted the study of many primary and secondary effects. As vehicle speed is increased, the ice and water pass through four characteristic modes of response, culminating in a wave effect at the higher speeds. It has been shown that the ice and water waves travel consistently at the speed of the vehicle. This factor has been used to modify a simple ice-wave theory, which then predicts a linear variation of wave frequency with vehicle speed that can be expressed in a universal form for deep-water conditions. The experimental measurements of frequency confirm this universal variation. The observed secondary effects include air-coupled flexural oscillations, hydrodynamic fluctuations and systematic variations in ice fracture intensity with vehicle speed. This last effect leads to the proposition of a new criterion of vehicle safety.

RÉsumé. Les mouvements de flexion d'une plaque de glace flottante provoqués par le trafic de véhicules. Une abondante série de tests a été exécutée sur une plaque de glace flottante sur un lac profond en eau douce. Des véhicules variés ont été pilotés le long d'un camion laboratoire à des vitesses très largement variées; ils ont provoqués plusieurs types de comportements caractéristiques de la glace et de l'eau, que l'on a enregistré et analysé en détail. Les essais ont été répétés à différents stades de la croissance de la glace pour prendre en compte le changement d'état physique. L'utilisation d'un capteur de vibration et d'un nouveau type de déflectomètre a permis l'étude de beaucoup d'effets primaires et secondaires. Lorsque la vitesse du véhicule augmente, la glace et l'eau passent par quatre types caractéristiques de réponses, la plus apparente étant un effet de vague aux plus grandes vitesses. On a montré que les ragues dans la glace et l'eau se propagent à la vitesse du véhicule. Ce facteur a été utilisé pour modifier une théorie simple de l'ondulation de glace, qui prévoit alors une variation linéaire de la fréquence de l'ondulation qui peut s'exprimer sous une forme universelle pour les conditions en eau profonde. Les mesures expérimentales de fréquence confirment cette variation universelle. Les effets secondaires observés comprennent les oscillations de flexion liés à l'air, les fluctuations hydrodynamiques et les variations systématiques dans l'intensité de fissurations de la glace avec la vitesse du véhicule. Ce dernier effet conduit à proposer un nouveau critère pour la sécurité des véhicules.

Zusammenfassung. Durchbiegung einer schwimmenden Eistafel durch bewegte Fahrzeuge. Ausgedehnte Versuchsreihen wurden auf einer schwimmenden Eistafel in einem tiefen Süsswassersee angestellt. Verschiedene Fahrzeuge wurden über eine instrumentierte Teststrecke mit Geschwindigkeiten, deren Bereich weit gespannt war, bewegt; dabei zeigten sich einige charakteristische Reaktionsabläufe in Eis und Was;er, die im Detail aufgezeichnet und analysiert wurden. Die Versuche wurden in verschiedenen Stadien des Eiswachstums wiederholt, um Änderungen in den physikalischen Bedingungen zu erfassen. Die Verwendung eines Vibrationsdetektors und eines neuartigen Neigungsmessers ermöglichte das Studium vieler Primärund Sekundäreffekte. Mit zunehmender Geschwindigkeit durchlaufen Eis und Wasser vier charakteristische Reaktionstypen, die bei den höheren Geschwindigkeiten in einem Welleneffekt gipfeln. Es zeigte sich, dass die Eis- und Wasserwellen sich durchwegs mit der Geschwindigkeit des Fahrzeuges fortpflanzen. Diese Tatsache wurde herangezogen, um eine einfache Eiswellentheorie so abzuändern, dass sie eine lineare Änderung der Wellenfrequenz mit der Fahrzeuggeschwindigkeit liefert, die sich bei grosser Wassertiefe in einer allgemein gültigen Form darstellen lässt. Die experimentelle Messung der Frequenz bestätigt diese allgemeine Änderung. Die beobachteten Sekundäreffekte umfassen Biegeschwingungen mit Luftresonanz, hydrodynamische Schwankungen und von der Fahrzeuggeschwindigkeit systematisch abhängige Änderungen der Bruchintensität des Eises. Der letztgenannte Effekt gibt Anlass zum Vorschlag eines neuen Kriteriums für die Sicherheit von Fahrzeugen.
\end{abstract}

\section{INTRODUGTION}

Winter roads and ice crossings have played an important part in Canada's northern transportation links for several years. In the province of Saskatchewan many northern communities and mine sites are largely dependent on winter-road supply routes for about four months in each year, and there is a growing demand for controlled ice crossings in the more heavily populated southern part. This applies particularly to communities normally served by ferries: their life-style and communications are substantially impaired in winter. 
With the prospect of introducing several ice crossings into the public road network, there arose an obvious need to establish reliable safety and maintenance procedures. This was accomplished in a detailed experimental study, conducted on a pilot ice crossing on Lake Diefenbaker in the winter of $1974-75$. The primary purpose of the study was to advise the Saskatchewan Department of Highways and Transportation on safety procedures, traffic control and maintenance. The findings have been compiled in a voluminous report by Eyre and Hesterman (1976), of which the major part is concerned with experimental measurements of ice response to static and moving vehicles.

The safety of a vehicle on a floating ice sheet depends primarily on ice thickness and condition. Gold (1960) has surveyed a large number of incidents of vehicles breaking through floating ice sheets and, from these, has developed an empirical relation between safe maximum vehicle mass and ice thickness. This gives a reliable basic criterion of vehicle safety that can be applied over a reasonable range of ice conditions. In addition to this basic criterion there are convincing reasons for supposing that vehicle speed could also be an important factor. The theories of Wilson (1958), Assur ([1962]) and Nevel (r97o) show that a vehicle travelling at a sufficiently high speed on floating ice will generate an ice wave whose amplitude tends to a considerable maximum at a defined critical speed. This speed also marks the onset of the wave effect. Wilson (r958) and Anderson (1958) have studied the effect experimentally in a small number of test runs. Their findings suggest that the amplitude effects are not dangerously large, but the limited range of their tests prohibits the drawing of any general conclusions. Aprocryphal tales from northern Canada suggest that vehicles can create "enormous" ice waves under certain circumstances. Making due allowance for poetic license, there is probably enough substance to these tales to justify the conclusion that visible ice waves can sometimes occur.

These considerations played a large part in shaping the experimental aspects of the Lake Diefenbaker study. The intention was to conduct systematic measurements of ice response to moving vehicles at several stages of ice growth; taking into account the variables of vehicle mass, vehicle speed, ice thickness, and effective elastic modulus of the ice. These aims were achieved, and surpassed, by using a new type of deflectometer. Many of the observed effects indicate useful directions of further research, and may be instrumental in modifying current theories of ice deflection behavior. Only the more important effects have been selected for presentation in this paper, and space limitations permit only a superficial treatment. Reference should be made to the report of Eyre and Hesterman (I976) for a more comprehensive treatment of the Lake Diefenbaker study.

\section{Details of THE EXPERIMENTAL SITE}

Lake Diefenbaker was created in 1967 by damming the South Saskatchewan River to form a hydro-electric reservoir. The decision to establish a pilot ice crossing on the lake was dictated by the severe shore effects expected to arise from the large decline in water level during winter. The average decline rate is about $44 \mathrm{~mm} \mathrm{~d}^{-1}$.

The ice crossing was constructed close to the line of the ferry near the town of Riverhurst, and a parallel experimental track was constructed alongside at a distance of $305 \mathrm{~m}$. Both were cleared regularly of snow, but no attempt was made to strengthen them in any way. The lake width is approximately $2 . \mathrm{I} \mathrm{km}$ at this location, and the maximum water depth is $46 \mathrm{~m}$. The mean water depth beneath the test track was $36.4 \mathrm{~m}$, which, for the purpose of ice response, can be regarded as a close approximation to semi-infinite depth. The mean ice thickness varied from $0.50 \mathrm{~m}$ to $0.73 \mathrm{~m}$ during the six-week period of the experimental programme, and was generally very uniform along the test track. 


\section{INSTRUMENTATION AND EXPERIMENTAL PROCEDURES}

The site was equipped with a comprehensive range of meteorological instrumentation, supplemented by measurements of ice accretion, ice ablation, snow thickness, and water level. Ice thickness was measured daily at 24 sites distributed along the crossing and test track. A new design of ice-thickness gauge was developed for this task, consisting of an iced-in graduated steel tube that could be released in a few seconds by passing d.c. current through the tube wall. The design was effective and most efficient.

An a.c.-powered laboratory was installed to one side of the test track, with instrumentation cables leading to three deflectometers stationed at precise intervals of $15^{2.4} \mathrm{~m}$ along the track. A vibration transducer was installed at one of these stations. Signals from the four instruments were recorded on a precision four-pen chart recorder. The vibration-transducer signal could be recorded directly or via a root-mean-square circuit, and was simultaneously passed through a pre-amplifier into a loudspeaker. The multiple deflectometer system was designed to measure the individual speeds of wave and vehicle, and to detect any development of the ice deflection patterns. The vibration transducer was included in an attempt to study any systematic trends in the intensity of noise emitted during ice fracture.

It was anticipated that the large water depth and the declining water level would create errors and operational problems if a conventional bottom-anchored deflectometer were to be used. A new design was developed, consisting of a sensitive, stable pressure transducer mounted $0.3 \mathrm{~m}$ below the ice-water interface in a tube attached rigidly to the ice sheet. The response of this type of deflectometer is considered below.

Tests were conducted at various stages of ice growth, covering a moderate range of ice thickness $(0.53$ to $0.73 \mathrm{~m})$ and a representative range of effective elastic modulus (2 to $\mathrm{I}_{3}$ $\mathrm{GN} \mathrm{m}^{-2}$ ). On each day of tests the experimental runs began with a light vehicle travelling at a low speed and progressing to higher speeds. The sequence was then repeated with vehicles of successively greater mass. Vehicle speeds ranged from o to $31 \mathrm{~m} \mathrm{~s}^{-1}$ and masses ranged from 2200 to $23500 \mathrm{~kg}$.

On each test run the vehicle accelerated as quickly as possible along $600 \mathrm{~m}$ of approach track, aiming to reach uniform test speed at least $\mathrm{I} 50 \mathrm{~m}$ before the first deflectometer station. The simultaneous response of the three deflectometers and the vibration transducer were recorded throughout the run. Many of the vibration transducer records were rendered useless by faults in the electronic equipment. More than 150 runs were conducted, and the records from practically all of these yielded useful data on several features of the ice and water response.

No attempt was made to measure the elastic modulus or bearing strength by direct techniques. The effective elastic modulus was derived from measurements of ice deflection under static loading conditions.

\section{RESPONSE OF THE DEFLECTOMETER}

A theoretical analysis of deflectometer response has been conducted for the case of sinusoidal motion of the ice sheet. The deflection at a fixed point on the ice sheet can be represented by:

$$
\delta=A \sin \omega t,
$$

where $\delta$ is the instantaneous ice deflection, $A$ is the amplitude and $\omega$ the angular frequency of the ice wave.

The pressure response of the deflectometer can be shown to be:

$$
P=-\epsilon+A \sin \omega t-\frac{\omega c A \sin \omega t}{g}+\frac{(\omega k \epsilon A)^{2} \cos \omega t}{2 g},
$$


where $P$ is the recorded pressure in equivalent water head, $\epsilon$ is the quiescent water head due to displacement of the transducer below the free water surface, $g$ is the acceleration due to gravity and $c$ and $k$ are the phase velocity and wave number of the ice wave.

The first sine term is the response to the ice motion (the true deflectometer effect) and the second is the response to the associated water wave. The cosine term is a hydrodynamic pressure effect produced by motion of the water relative to the deflectometer, and assumes that the pressure is sensed through a hole in a downward-facing surface. The relative magnitudes of these terms vary with frequency, giving three cases of particular interest:

\section{Case. I. Slowly varying ice motion}

The last two terms in Equation (2) become negligible and the fluctuating component of the deflectometer response gives a true record of the ice motion.

\section{Case II. Primary waves associated with vehicle motion}

The cosine term remains negligible and Equation (2) reduces to

$$
P=-\epsilon+\left(\mathrm{I}-\frac{\omega c}{g}\right) \cdot A \sin \omega t .
$$

The deflectometer responds to both the ice and water waves. The latter generally predominates, and for all practical situations the bracketted expression in Equation (3) takes a negative sign, producing a deflectometer response in counter-phase to the ice wave. Due to the simple form of Equation (3) the deflectometer response can be analysed easily to yield the amplitudes of both ice and water waves, making the instrument doubly effective in this mode of operation.

\section{Case III. High-frequency wave motion}

In this situation all the terms in Equation (2) are significant, but the cosine term predominates. The resulting deflectometer response displays a high inherent amplification and an irregular phase shift relative to the ice motion. The amplification effect can be of value in revealing secondary high-frequency waves which usually have amplitudes too small to be detected by conventional deflectometers. Since the cosine term arises from water motion relative to the deflectometer, the effect can be eliminated by appropriate design changes. This is advantageous when secondary effects tend to obscure the primary-wave response.

The validity of the various terms in Equation (2) was confirmed by several tests conducted during the experimental programme. The deflectometer design was eventually modified to eliminate the hydrodynamic cosine term; simplifying the response to that given in Equation (3). This was successful in removing high-frequency ice-motion effects except those that, logically, could originate only from random pressure fluctuations in the water. The deflectometer response equations should therefore be modified to account for this practical departure from the theoretical, non-viscous case:

$$
P=-\epsilon+\left(\mathrm{I}-\frac{\omega c}{g}\right) \cdot A \sin \omega t+\tilde{p},
$$

where $\tilde{p}$ represents an undetermined random pressure fluctuation; the significance of which is considered later.

Random pressure fluctuations were found to be insignificant ahead of the vehicle, but were appreciable, and often obtrusive, in the immediate vicinity of the vehicle and in its wake. This was the major disadvantage of the deflectometer. In practically all cases the primary ice motion around the vehicle was totally obscured by these random fluctuations, and this was particularly true of the records obtained from tests with heavier vehicles. A limited series of 
tests was conducted with a bottom-anchored deflectometer during the winter of $1975-76$ to remedy this deficiency in the experimental data. Of all the tests conducted at Lake Diefenbaker, this short series gave the only reliable data on ice deflection in the immediate vicinity of the vehicle.

The major advantage of the deflectometer lies in its ability to measure water-wave as well as ice-wave effects. The amplitude of the ice wave decreases sharply to a barely detectable level as the vehicle speed increases above the critical value, but there is little corresponding reduction in the amplitude of the water wave. The deflectometer uses this situation to advantage by registering wave effects when the ice wave is virtually non-existent. This has added considerably to the range and value of the Lake Diefenbaker data.

\section{SumMary OF THE PRIMARY IGE AND WATER RESPONSE}

A moving vehicle generates an inordinately large number of effects in the ice sheet and water. These can be seen in better perspective if the discussion of results is preceded by a general, descriptive summary of the more important features. It is convenient at this stage to distinguish between primary and secondary effects. The primary effects are those which have relatively low frequencies and are propagated at speeds comparable with that of the vehicle. Secondary effects have relatively high frequencies, much higher speeds of propagation, and often display random behaviour.

When a vehicle travels across the ice at successively higher speeds, the ice and water pass through four characteristic modes of primary response. In detail, these may vary according to vehicle mass, ice thickness or effective elastic modulus, but the basic pattern of the response depends wholly on the vehicle speed. Figure I shows, in schematic form, the ice-deflection

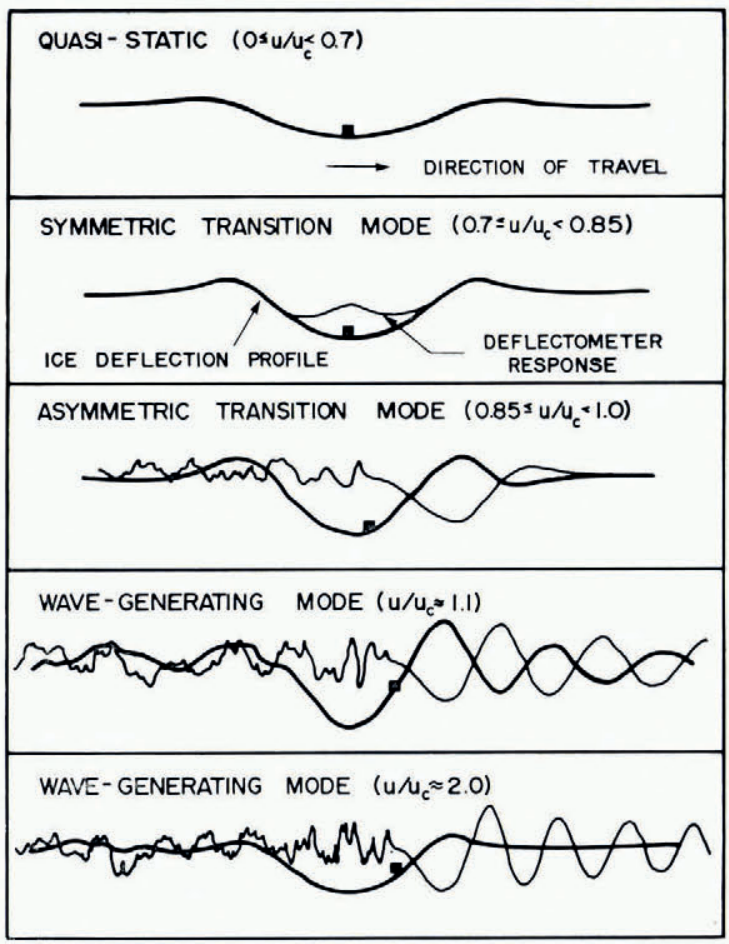

Fig. I. Ice-deflection profiles and deflectometer response at various vehicle speeds. 
profile and the deflectometer response typical of each mode of behaviour. The approximate speed range of each mode is given in brackets, and is expressed in terms of $u / u_{\mathrm{c}}$, where $u$ is the vehicle speed and the subscript c denotes the critical value.

The quasi-static mode occurs at the lower vehicle speeds. The ice-deflection profile remains symmetrical about the moving vehicle point, and its shape is not changed significantly from that of the static profile defined by Hertz (1884). In this mode the deflectometer response coincides with the ice-deflection profile, indicating that no pressure disturbances are generated in the water.

Transition effects become apparent as the vehicle speed is further increased. The depression becomes deeper and narrower, and the rim around the depression rises progressively above the neutral ice position. In this symmetric transition mode, the ice-deflection profile retains its symmetry about the vehicle position. The deflectometer response begins to diverge from the deflection profile at this stage, and records an apparent deflection peak at the vehicle location. The implication is that the ice depression is moving fast enough to create a waterpressure disturbance in the form of a negative pressure pulse.

The symmetric transition mode encompasses a fairly small range of vehicle speeds and shortly gives way to the asymmetric transition mode. The main ice depression continues to become deeper and narrower, and two asymmetric features start to develop: the forward rim of the ice depression begins to evolve into a wave-like pattern, and the centre of the depression lags increasingly behind the vehicle. The deflectometer displays the predicted counter-phase response ahead of the vehicle, but the response behind the vehicle degenerates progressively into an irregular signal with high-frequency components and intermittent periodic effects. This is suggestive of a hydrodynamic wake.

The asymmetric transition mode blends fairly continuously into the wave-generating mode at the critical speed, and the main depression achieves maximum depth and minimum width at this point. At speeds slightly above critical there is a well-defined wave train on the ice ahead of the vehicle, accompanied by an equally well-defined water wave in counter-phase. The vehicle assumes a position approximately half-way up the forward slope of the main depression, and retains this position at all higher vehicle speeds. The ice behind the main depression displays an irregular deflection pattern with an occasional periodic component. The deflectometer continues to record a hydrodynamic wake effect, but of higher amplitude.

With a further increase of vehicle speed above the critical value, the ice wave soon disappears, though the water wave continues with little change in amplitude. The main depression tends to recover its quasi-static profile, but the vehicle maintains its position ahead of the centre of the depression. The hydrodynamic wake persists with no apparent change, and the ice behind the depression tends to a static condition.

The boundaries between the four characteristic modes of response are marked by three characteristic speeds. The first two have been termed the onset speed $u_{0}$ and the peak fracture speed $u_{\mathrm{pf}}$, which have other physical implications that will presently become clear. The third is the critical speed defined in earlier theoretical treatments.

\section{SumMARY AND DISGUSSION OF RESULTS}

\section{Relative speeds of propagation}

A comparison of records from the three deflectometer stations showed that, during each test run, the vehicle maintained the same position relative to the ice-deflection profile and the water-disturbance profile throughout the run. This was confirmed for all vehicle speeds and masses. The conclusion is that the primary ice and water disturbances are always propagated at the speed of the vehicle, irrespective of the mode of ice and water response.

This simple result has far-reaching consequences. In particular, the primary ice waves generated by moving vehicles are always constrained to move at the speed of the vehicle, and 
are to be regarded as "forced" waves rather than the free dispersive waves assumied in some theories. The influence of this factor on the theoretical work of Wilson (1958) is examined later.

\section{General features of wave response}

Detailed checks of the deflectometer response confirmed that the frequencies of the ice wave and the corresponding water wave were always identical, as prescribed in Equation (2). The more extensive records of water-wave response were analysed to identify any systematic changes of frequency along the wave train. A few records showed an orderly reduction of frequency with distance ahead of the vehicle: the reduction rate being about $5 \%$ per cycle. Generally, however, there was no significant frequency trend. Therefore, the waves generated by a moving vehicle are essentially monotonic.

Dispersive wave theories lead to the conclusion that a moving vehicle can generate a trailing wave with a frequency lower than that of the leading wave. Intermittent trailing waves were evident on a few records, but their frequencies showed no consistent trend. It is possible that any such tendency to wave action is destroyed by hydrodynamic fluctuations in the wake of the vehicle.

\section{Variation of wave frequency with vehicle speed}

The study of this effect proved to be the most rewarding aspect of the whole experimental programme. Extensive data were obtained on each test day, covering a wide range of vehicle speeds and masses. Figure 2 shows the frequency-speed variation observed on two days. The variation is clearly linear over the experimental range, and a regression analysis showed that the data for individual vehicles could be fitted to individual straight lines with a correlation coefficient never less than 0.995 . On most days the lines for individual vehicles coincided very

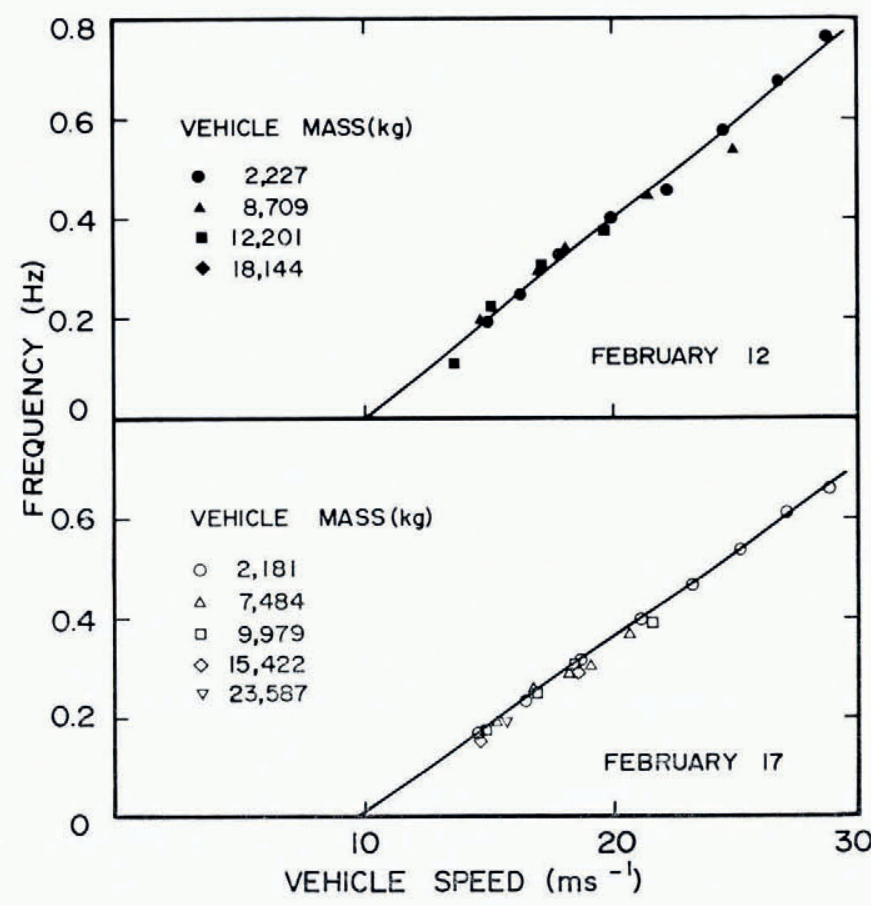

Fig. 2. Variation of wave frequency with vehicle speed on two test days. 
closely, as demonstrated by Figure 2, but on two days there was a significant spread. This can be attributed to variations in ice condition throughout the day-always a confounding factor in experiments on floating ice sheets.

The intercept and slope of the frequency-speed lines varied from day to day in an apparently disorderly way. In a later theoretical analysis it is shown that, if the variables are transformed into dimensionless parameters, all the data points can be correlated by a single, universal line.

\section{The amplitude of the water wave}

If the water-wave effect is expressed in terms of equivalent water head, the wave amplitude can be defined as one-half of the head difference between the major peak and trough. This amplitude was found to be essentially independent of vehicle speed for each vehicle used in the tests. The ice conditions on I 7 February were apparently very stable, and the water-wave amplitudes on this date were found to be essentially independent of vehicle mass. The data obtained on all other days showed a variation with vehicle mass, probably as a result of changes in ice condition between successive vehicle tests.

\section{Range and evolution of the water wave}

The water body ahead of the vehicle is influenced by wave action over a distance which has been termed the range. The amplitude of the water wave decays to zero over this range in an approximately linear fashion. Ranges varied from 200 to $400 \mathrm{~m}$.

A comparison of records from the three deflectometers indicated that, in most cases, the range was increasing with time of travel. For lighter vehicles the range was relatively large and the rate of increase was relatively small. Heavier vehicles demonstrated an opposite trend. These factors suggest that the range variation can be represented by:

$$
R=R_{\infty}[\mathrm{I}-\exp (-T / B)],
$$

where $R_{\infty}$ denotes the range after an infinite time of travel, $T$ is the time of travel and $B$ is a parameter which increases with vehicle mass.

It can be concluded that heavier vehicles are less effective as a coherent source of waterwave action, probably because they induce violent water motion which is dissipated in a turbulent form.

\section{Amplitude of the ice wave}

The amplitude of the ice-wave is defined in a manner similar to that of the water wave, and it is to be emphasized that the ice wave is a feature of the ice motion quite distinct from the dish-like depression around the vehicle.

The only consistent data on ice-wave amplitudes were obtained under the apparently stable ice conditions prevailing on 17 February. The amplitudes generated on this date by the lightest vehicle were too small to be measured with any degree of accuracy. The data provided by the heavier vehicles are summarized in Figure 3. This shows the variation of amplitude with vehicle speed, where the amplitude $A$ has been normalized to $\delta_{0}$, the maximum ice deflection produced by the corresponding vehicle at rest. In this form, the amplitudes induced by the several vehicles fall on a common curve represented closely by:

$$
\frac{A}{\delta_{0}}=0.26\left(\frac{u}{u_{\mathrm{c}}}-\mathrm{I}\right)^{-\frac{2}{3}} \text {. }
$$

The amplitudes observed on all other test days showed a similar decrease with vehicle speed, and the magnitudes were always less than the values given by Equation (6). An attempt to obtain a general correlation was defeated by the effects of varying ice conditions. 


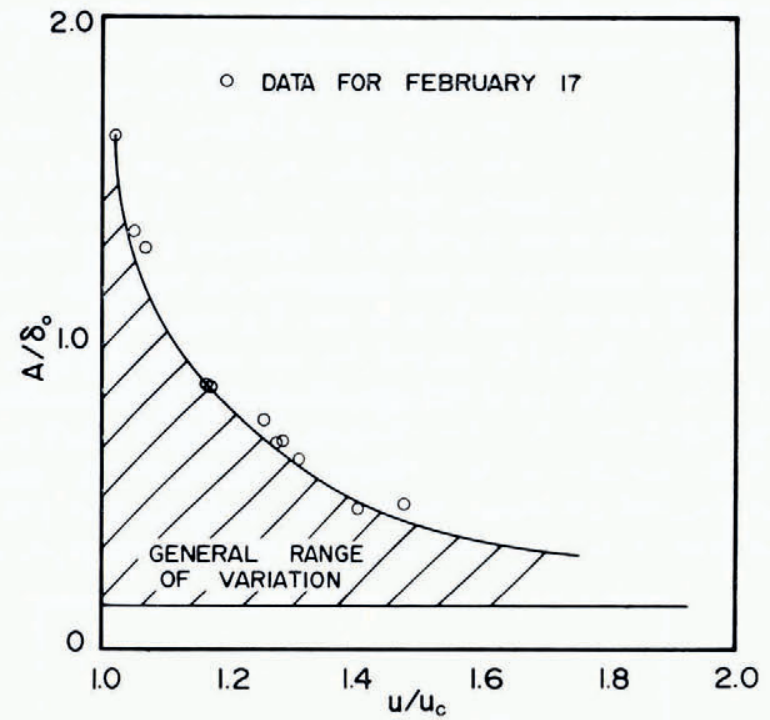

Fig. 3. Normalized ice-wave amplitude as a function of vehicle speed.

7. Effect of vehicle speed on the shape of the main depression

A vehicle at rest on ice creates a characteristic, dish-like depression. This retains a distinct identity at all vehicle speeds, as shown in Figure I, though it undergoes systematic shape changes and occasionally displays superimposed secondary effects. For reasons given earlier, the study of the shape of this depression was restricted to a short series of runs conducted during the winter of $1975^{-76}$ with a $5443 \mathrm{~kg}$ vehicle.

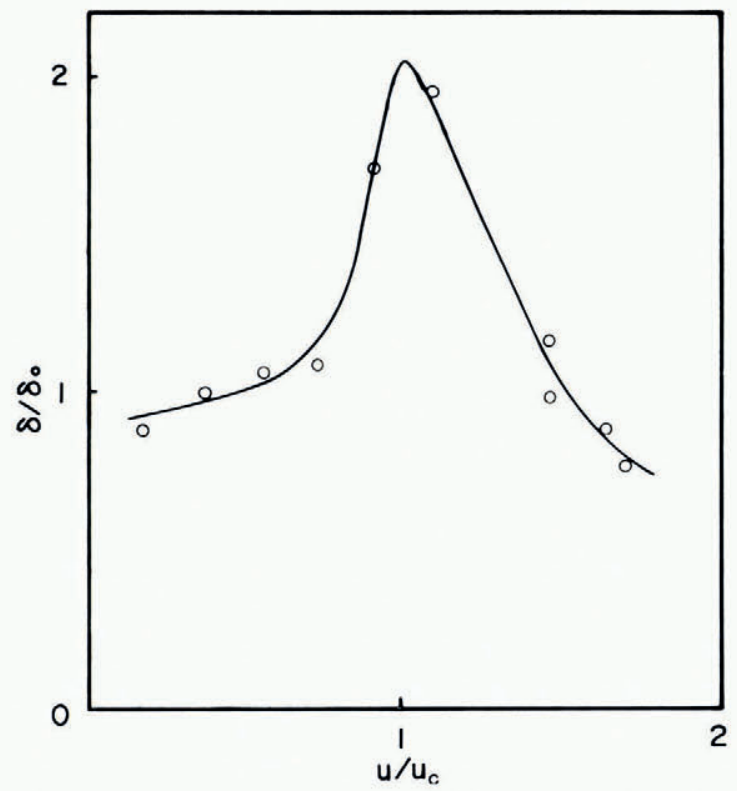

Fig. 4. Variation of ice depression depth with vehicle speed (from runs with a vehicle of mass $5443 \mathrm{~kg}$ ). 
The maximum ice deflection always occurs at the centre of the depression and is denoted by $\delta$. Figure 4 shows the variation of $\delta / \delta_{0}$ with vehicle speed, where $\delta_{0}$ is the maximum ice deflection when the vehicle is at rest. The general shape of the curve, with a maximum at the critical speed, is consistent with the observations of Wilson (1958) and the theoretical predictions of Nevel (1970). It will be observed that the greatest deflection is about twice the static value. This corresponds to a maximum ice deflection of about $25 \mathrm{~mm}$ in this situation.

Figure 5 shows the variation of the width of the depression with vehicle speed. The width of the depression $\lambda$ has been expressed in the dimensionless form $\lambda / L$, where $L$ is the characteristic length of the ice. When the vehicle is at rest, $\lambda / L$ has a theoretical value of 7.8 , based on the work of Hertz ( 1884 ). It will be noted that the variation displays a minimum at the critical speed, and generally displays a trend opposite to that of the maximum deflection. This leads to an interesting hypothesis: that the observed changes of depth and width can be described simultaneously by postulating an "effective" characteristic length that varies with vehicle speed. An analysis of the experimental data suggests that this hypothesis may be correct, but the limitations of the data do not permit an irrefutable proof.

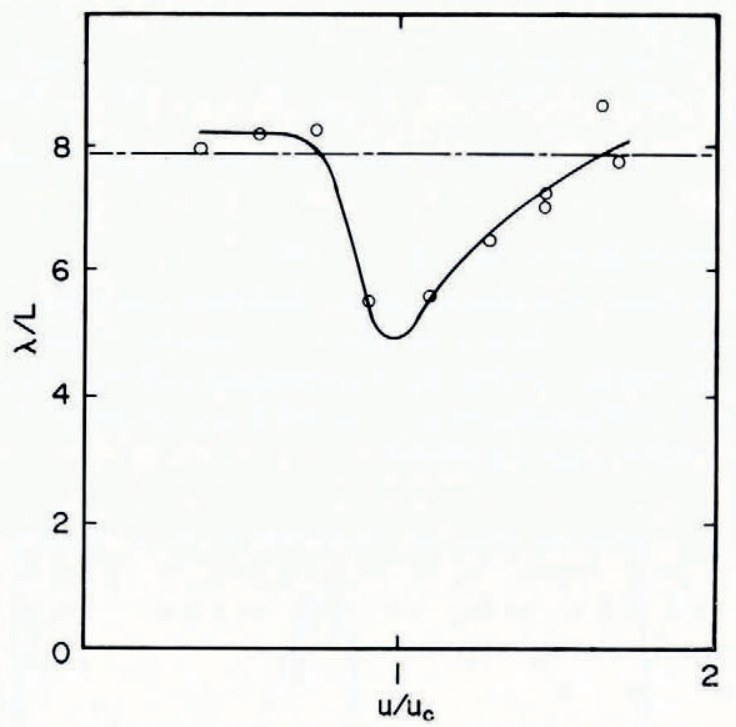

Fig. 5. Variation of ice depression width with vehicle speed (vehicle of mass $5443 \mathrm{~kg}$ ).

\section{Ice fracture intensity}

Preliminary tests demonstrated that the vibration transducer was responding almost totally to noises generated in the ice by fracture events. It can be argued that the intensity of this noise is related to ice fracture rate, and that the total noise generated within range of the transducer is a good indication of ice fracture intensity (i.e. the number of fractures generated per unit area of ice).

Equipment failure has prevented a systematic study of the effect. The few reliable measurements are presented in Figure 6, which shows the variation of total noise signal with vehicle speed for various vehicle masses. With heavier vehicles there is a clear tendency to maximum noise (maximum fracture intensity) at a speed significantly below critical. This was confirmed qualitatively in all runs with heavy vehicles-the loudspeaker noises were of alarming intensity at vehicle speeds slightly below critical. The data for light vehicles show an anomalous effect, and there is a general, and expected, increase of maximum noise with vehicle mass. 


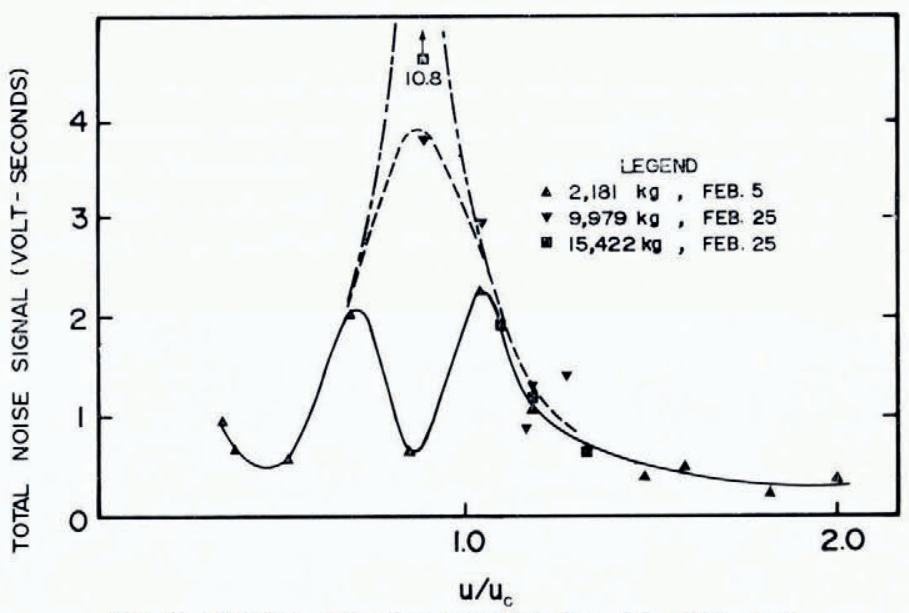

Fig. 6. Variation of fracture-generated noise with vehicle speed.

The four modes of ice response in Figure I give some indication of the possible origin of the effect. The maximum fracture intensity occurs at a speed that coincides closely with the boundary speed separating symmetric and asymmetric ice behaviour. Therefore, it is reasonable to assume that this boundary can be defined by $u_{\mathrm{pf}}$, the peak-fracture speed. The close coincidence of the two effects suggests that, at this vehicle speed, there is a marked change in the response of the internal ice structure to applied stress. This further suggests that the rheological peculiarities of the ice may be the deciding factor at this point.

Though the measurements of ice fracture effects are admittedly incomplete and unsatisfactory in many respects, it is believed that they indicate an effect of major importance. As a criterion of ice safety, the fracture intensity is clearly more reliable than the amplitude of elastic ice waves. Therefore, for a vehicle travelling on a floating ice sheet, the critical speed $u_{\mathrm{c}}$ is less dangerous than the peak-fracture speed, given by:

$$
u_{\mathrm{pe}} \approx 0.85 u_{\mathrm{c}} .
$$

The major features of the ice response are summarized schematically in Figure 7 , which indicates the relative variation of fracture intensity and maximum ice deflection.

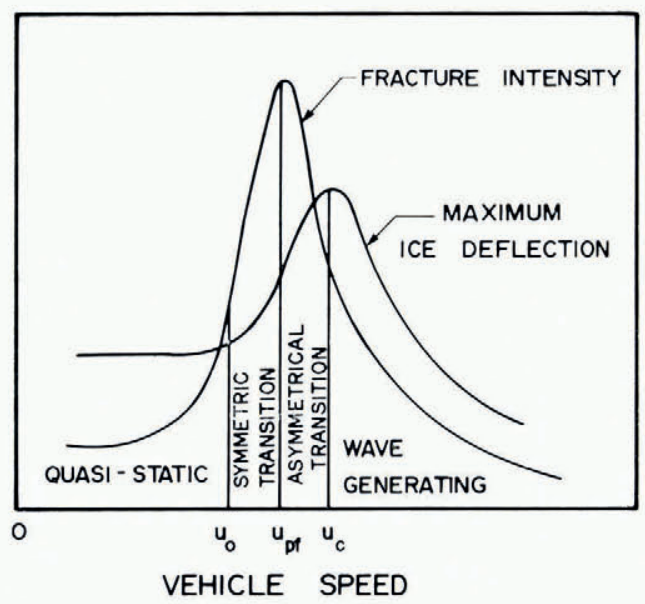

Fig. 7. Schematic comparison of fracture intensity and ice-deflection variations. 


\section{Air-coupled flexural waves}

Isolated fracture noises were invariably accompanied by rapid fluctuations of the deflectometer response. These were investigated by running the chart recorder at high speed. The fluctuations proved to be lightly damped oscillations, undoubtedly initiated by the fracture event. The amplitude of the oscillations was generally less than I $\mathrm{mm}$, and they would have been undetectable had it not been for the inherent amplification of the deflectometer.

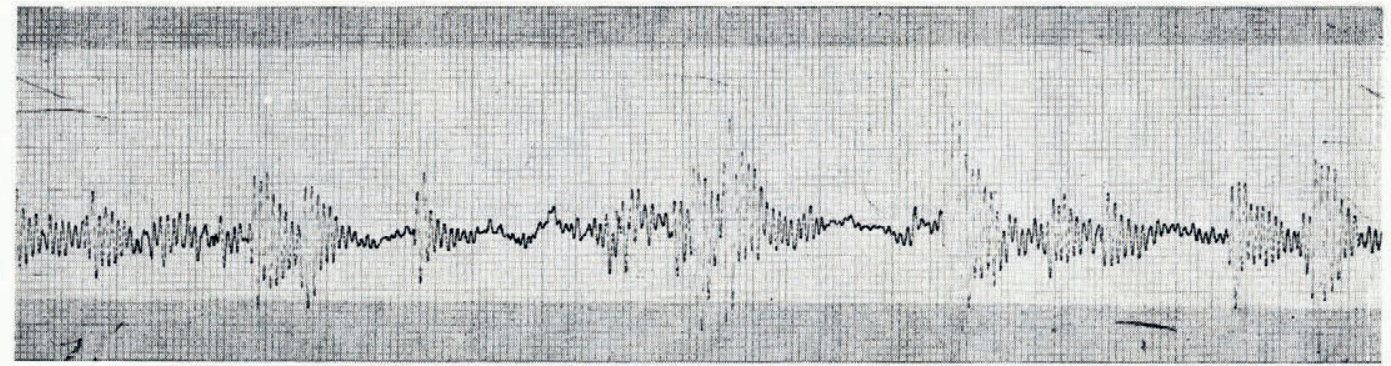

Fig. 8. Air-coupled flexural waves induced by a succession of ice fracture events.

Figure 8 is taken from an actual chart record, and shows several such oscillations originating from a moderately intensive sequence of fractures. The frequency of oscillation varied from 40 to $45 \mathrm{~Hz}$ over several days of tests. This is consistent with the theories of Ewing and Crary (1934) and of Press and others (1950), which show that, for the conditions prevailing at Lake Diefenbaker, air-coupled flexural waves should have a frequency in the range 42.3 to $57.8 \mathrm{~Hz}$. Therefore, it can be assumed that an ice-fracture event generates oscillations of this type.

\section{I0. Secondary flexural wave effects}

Many chart records displayed wave packets that appeared to travel at relatively high speeds over large distances with no perceptible decrease in amplitude. The frequency varied from day to day over a fairly small range of 2.4 to $3.5 \mathrm{~Hz}$. The group velocity was difficult to establish accurately, but was within the range 180 to $200 \mathrm{~m} \mathrm{~s}^{-1}$. There appeared to be a definite threshold vehicle mass of about $8500 \mathrm{~kg}$, below which the waves were not generated. One sequence of tests indicated a possible dependence of wave frequency on vehicle speed, as shown in Figure 9. Below critical speed the frequency is essentially constant, but there is a possible "forcing" effect at higher speeds.

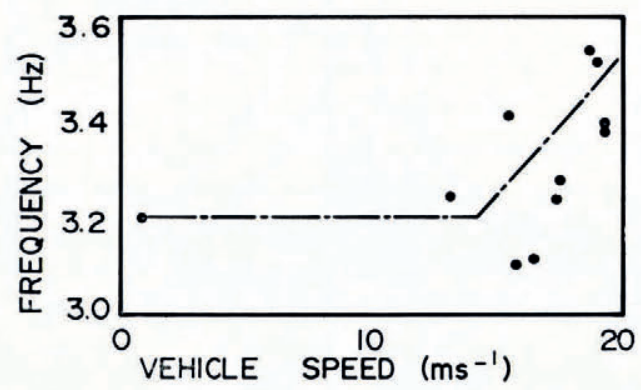

Fig. 9. Effect of vehicle speed on frequency of flexural oscillations. 
The flexural wave theory of Ewing and Crary (1934), applied to the Lake Diefenbaker conditions, predicts a group velocity of $165 \mathrm{~m} \mathrm{~s}^{-1}$ for a wave of assumed frequency $3.2 \mathrm{~Hz}-$ showing tolerable agreement with the observed velocity.

In one situation the flexural wave frequency coincided with the natural frequency of the vehicle suspension, causing a severe resonance effect which resulted in large ice oscillations and a partial loss of vehicle control.

\section{I. Hydrodynamic fluctuations}

Fluctuations of relatively high frequency often obscured the primary response of the deflectometers, particularly in the neighbourhood of the vehicle and in its wake. These effects persisted even when the deflectometer was modified to eliminate the effects of watervelocity fluctuation, suggesting that the fluctuations were due to hydrodynamic pressure disturbances. These were influential in disrupting any tendency to wave action in the vehicle wake.

It is tempting to describe these effects as "random" or "turbulent". However, in one series of tests, two successive runs were made by the same vehicle at the same speed, and the two chart records show an incredible and almost perfect repeatability of the fluctuation pattern. This phenomenon, together with the occasional periodicity of the effect, suggests that the vehicle generates an orderly, vortex-like disturbance in the water. The onset of the effect could possibly be defined by a critical Reynolds number; combining the variables of vehicle speed and ice deflection.

\section{The THEORETICAL RELATION BETWEeN VEHICLE SPEED AND WAVE FREQUENGY}

Wilson (1958) has derived the following relation between phase velocity $c$ and wave number $k$ for a wave generated by a vehicle travelling on a floating ice sheet:

$$
c^{2}=\frac{g}{k}\left(\mathrm{I}+L^{4} k^{4}\right) \cdot \tanh k H,
$$

where $g$ is the acceleration due to gravity, $L$ is the characteristic length of the ice, and $H$ is the water depth.

Wilson introduces the vehicle speed into Equation (8) by an ingenious though somewhat complicated construction that results in two waves travelling at individual group velocities, each different from the vehicle speed. This has not been confirmed by the Lake Diefenbaker study, which consistently displayed a single, non-dispersive wave travelling at the same speed as the vehicle. Therefore, the phase velocity $c$ in Equation (8) can be replaced by the vehicle speed $u$.

The problem now is to reconcile the non-linear theoretical relationship of Equation (8) with the observed linear relation between wave frequency and vehicle speed. The mathematics is simplified by defining dimensionless forms of the vehicle speed $u$, the wavelength $\Lambda$, and the frequency $f$ as follows:

$$
U=\frac{u}{(g L)^{\frac{1}{2}}}, \quad X=\frac{\Lambda}{2 \pi L}, \quad F=2 \pi f \cdot\left(\frac{L}{g}\right)^{\frac{1}{2}} .
$$

The dimensionless parameters are related in the same way as the conventional wave variables:

Equation (8) then becomes:

$$
U=F X
$$

$$
U^{2}=\left(X+X^{-3}\right) \cdot \tanh \left(\frac{H}{X L}\right),
$$




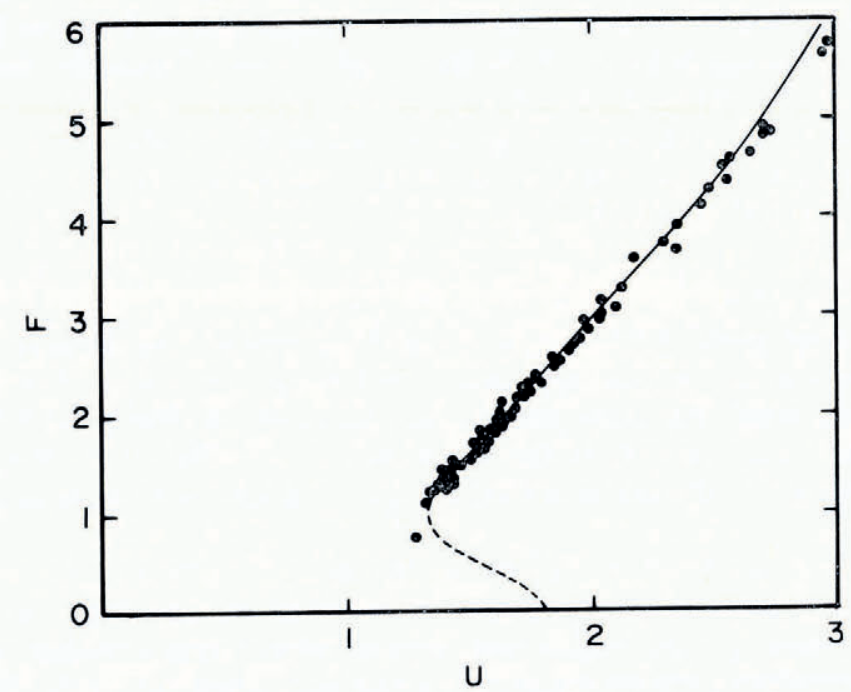

Fig. Io. Correlation of experimental data with theoretical universal curve.

in which $X$ is clearly a transcendental function of $U$, with $H / L$ occurring as a parameter. Equations (IO) and (I I) can be solved numerically to give the relation between $F$ and $U$ for various values of $H / L$. Figure io shows the form of this variation for the Lake Diefenbaker conditions, where $H / L$ was typically 3.2. The variation of $F$ with $U$ is approximately linear over a wide speed range above the critical point, showing qualitative agreement with the experimental observations. A regression analysis shows that the linear portion of the curve can be represented by:

$$
F=2.73 U-2.45
$$

Using Equations (9) to restore the real variables, this becomes

$$
f=0.434 \frac{u}{L}-\frac{\mathrm{I} .22}{L^{\frac{1}{2}}},
$$

where $f$ is the frequency in $\mathrm{Hz}$, and $u$ is the vehicle speed in $\mathrm{m} \mathrm{s}^{-1}$.

Any changes in the value of $H / L$ have no significant effect on the form of Equations (12) and (13), provided that $H / L$ is greater than 2.0. Therefore, Equation (12) can be regarded as universal for deep water.

To test the theory, the experimental variations of $f$ with $u$ were compared with Equation (13), using values of $L$ determined from static loading tests. The errors in $L$ were known to be large, and as a result the agreement was less than satisfactory. However, it will be noted that, in Equation (13), the single variable $L$ has to account simultaneously for the slope and intercept of the frequency-speed line. Therefore, if Equation (13) can be made to fit the experimental data accurately by choosing a suitable value of $L$, this can be taken as an acceptable proof of the theory. This approach was applied to each sequence of runs, and produced values of $L$ that were always within 10\% of the corresponding values obtained from static loading tests. At the same time, the "derived" values of $L$ gave a remarkably good agreement between the experimental data and Equation (13). This is demonstrated convincingly in Figure 10, where the experimental data have been converted into dimensionless form using the "derived" values of $L$, and have then been plotted against the universal deep-water curve.

This leads to two conclusions. First, the experimental data confirm the validity of Equation (12), which applies to a deep-water situation and is based on a simple modification of 
Wilson's theory. Secondly, the characteristic length of the ice can be determined with reasonable precision by measuring the frequency of the ice wave induced by a vehicle travelling at a known speed, and by substituting the values of $f$ and $u$ in Equation (1 3 ) for deep water, or in Equations (IO) and (II) in the general case-though the validity of the theory has not been confirmed for shallow-water configurations.

Regarding the critical speed, the lack of any marked change in the ice response makes it difficult to establish this with certainty. The data points in Figure ro give an indirect confirmation of the theoretical critical speed for deep water. This is defined by:

$$
u_{\mathrm{c}}=\mathrm{I} \cdot 3 \mathrm{I}(\mathrm{g} L)^{\frac{1}{2}} \text {. }
$$

Nevel's theory (1968), applied to the same situation, predicts a value:

$$
u_{\mathrm{c}}=\mathrm{I} .27(\mathrm{gL})^{\frac{1}{2}} \text {. }
$$

\section{Conclusions}

The Lake Diefenbaker study has produced a fairly broad range of experimental data on the response of a floating ice sheet to moving vehicles, and it has been shown that the data tend to confirm the existing theories. New types of instrumentation have provided interesting clues to several hitherto unobserved features of ice and water response. Typically, this has produced more questions than answers.

The measurements of hydrodynamic fluctuations and ice fracture severity are of particular interest, and suggest fruitful lines of experimental research and theoretical development. The ice fracture severity appears to be a sound criterion for future evaluations of the safety of vehicles on ice, but a proper understanding of the effect will require a departure from the existing elastic theories. In this, the growing body of knowledge on non-elastic ice behaviour should be helpful. It is earnestly hoped that this paper will promote further studies of these interesting and important effects.

\section{Acknowledgements}

This work was conducted at the request of Mr R. W. Culley, Director of the Research Branch, Saskatchewan Department of Highways and Transportation. It is a pleasure to acknowledge his support and his agreement to the presentation of this paper.

\section{REFERENGES} Anderson, D. L. 1958. Preliminary results and review of sea ice elasticity and related studies. Transactions of the
Engineering Institute of Canada, Vol. 2, No. 3, p. I I6-22.

Assur, A. [1962.] Traffic over frozen or crusted surfaces. (In Meccanica dei sistemi suolo-vericolo. Atti del I Convegno Internazionale del Movimento fuori strada, Torino-Saint Vincent, 12-16 Giugno 1961 . Torino, Edizioni Minerva
Tecnica, p. 91 1 -23.)

Ewing, M., and Crary, A. P. 1934. Propagation of elastic waves in ice. Part II. Physics, Vol. 5, No. 7, p. 18 1-84. Eyre, D., and Hesterman, L. I976. Report on an ice crossing at Riverhurst during the winter of $1974-75$.
Saskatchewan Research Council. Report No. E76-9. Gold, L. W. r 960 . Field study on the load bearing capacity of ice covers. Woodland Review (Pulp and Paper
Magazine of Canada), Vol. 6i, No. 5, p. $153-54,156-58$.

Hertz, H. [R.] 1 884 . Über das Gleichgewicht schwimmender elastischer Platten. Annalen der Physik und Chemie,
Neue Folge [Wiedemann], Bd. 22, Ht. 7, p. 449-55. Neue Folge [Wiedemann], Bd. 22, Ht. 7, p. 449-55.

Research Report 265 .

Press, F., and others. 1950. Air coupled flexural waves in floating ice, by F. Press, M. Fuing A. P. Crary, S. Katz and 7. Oliver. Bedford, Mass., Geophysics Research Directorate, U.S. Air Force Cambridg, A. P. Crary, S. Katz and (Geophysics Research Papers, No. 6.)

Wilson, J. T. I958. Moving loads on floating ice sheets. Ann Arbor, Michigan, University of Michigan Research Institute. (UMRI Project 2432.) 


\section{DISCUSSION}

D. E. Nevel: You have contributed a number of valuable ideas and good data to a problem which has not been investigated very much. The fact that the water and ice responses travel at the same speed as the vehicle may be due to the fact that the tests were run under steadystate conditions. If the vehicle speed were to change during the test a transient effect would be observed in which the waves would travel at a speed different from that of the vehicle.

The fact that maximum cracking occurs at 0.85 of the critical speed is an interesting point. The theoretical solution predicts that it should occur at the critical speed, but I suspect that the mathematical solution has not included all the important physical processes. However, this concept somewhat agrees with the forced-vibration effects observed on a floating ice sheet, where the critical frequency for stress is lower than that for deflection.

D. Eyre: I would certainly agree with both of Dr Nevel's comments. The water/ice response should travel at the same speed as the vehicle under steady-state conditions, and my emphasis of this factor was designed to correct at least one existing theory which postulates that the speeds should differ.

Regarding the second pcint, the ice displays maximum curvature at the critical speed and, assuming a linear relation between strain and fracture rate, one would expect the maximum fracture rate to occur at that speed. The observed occurrence of the peak in fracture rate at a lower speed suggests that the rate of loading may be an important factor in describing this effect. The peak fracture speed coincides (or nearly does) with the onset of a phase shift between the vehicle and the centre of the main ice depression. Therefore there are two effects here, possibly related, that deserve further investigation. A proper understanding of the ice mechanisms under these conditions should be rewarding from both an academic and a safety point of view. 